\section{Registration of Pearl Millet Parental Lines ICMA 92666 and ICMB 92666 with Multiple Disease Resistance}

ICMB 92666 (Reg. no. PL-31, PI 596509) pearl millet [Pennisetum glaucum (L.) R. Br.] is the maintainer line of a male-sterile line ICMA 92666 (Reg. no. PL-32, PI 596510). ICMA 92666 and ICMB 92666 were released in 1996 by ICRISAT Asia Center, Patancheru, AP, India, for use as seed parents in hybrid breeding programs. These lines are resistant to ergot (caused by Claviceps fusiformis Loveless), smut [caused by Moesziomyces penicillariae (Bref.) K. Vánky; syn. Tolyposporium penicillariae Bref.], and downy mildew [caused by Sclerospora graminicola (Sacc.) J. Schröt.].

The male-sterile line, ICMA 92666, derives its $A_{1}$ cytoplasm from ICMA-1 (81A) (1). ICMB 92666 was developed from a BC $_{1}$ population [ICMPES $34 \times(843 \mathrm{~B} \times$ ICMPES 34$)]$. 843B (= BKM 2068 ) is a $d_{2}$ dwarf, early-maturing, large-seeded maintainer line of male-sterile line 843A (= AKM 2068). 843A and 843B were developed at the Fort Hays Experiment Station, Kansas State University, and introduced into India in 1982 by ICRISAT. $843 \mathrm{~B}$ is a good general combiner, but is highly susceptible to ergot, smut, and downy mildew. ICMPES 34, developed at ICRISAT Asia Center (IAC) as an ergot resistance source, is a tall, late-maturing line with high levels of resistance to ergot, smut, and downy mildew (2).

During the 1985 cool-dry season, $432 \mathrm{BC}_{1} \mathrm{~F}_{1}$ plants selected from among $>1000$ plants on the basis of early flowering, shorter height, and good tillering, were screened for ergot. Sixty-four of these $\mathrm{BC}_{1} \mathrm{~F}_{1}$ plants that had $<10 \%$ ergot and medium to large seed size were selected and evaluated as $\mathrm{F}_{2}$ progeny rows during the 1986 rainy season. One of the progenies $\left(F_{2}-155\right)$ flowered in 45 $\mathrm{d}$ and had $2 \%$ ergot, whereas $843 \mathrm{~B}$ (control) flowered in $39 \mathrm{~d}$ and had $85 \%$ ergot. Further pedigree selection within this progeny led to the identification of an $\mathrm{F}_{4}$ progeny that had $<1 \%$ ergot $(95 \%$ in 843B) during the 1987 rainy season. When crossed onto malesterile line $81 \mathrm{~A}$, this $\mathrm{F}_{4}$ progeny produced a male-sterile hybrid. Eleven additional generations of bulk pedigree selection for agronomic traits in this $F_{4}$ progeny and 10 generations of concurrent backcrossing onto male-sterile backcross progenies led to the development of ICMA 92666 and ICMB 92666 during the 1992 warm-dry season. Intermittent evaluation of resistance to downy mildew and ergot during the generations of selfing was done for the $\mathrm{F}_{4}$-derived lines. Ergot severity in these lines ranged from 1 to $14 \%$, compared with 75 to $95 \%$ in $843 \mathrm{~B}$.

Under high disease pressure in four greenhouse seedling inoculation tests and in a disease nursery at Mysore in southern India, ICMB 92666 registered 3 to $13 \%$ downy mildew incidence, compared with 58 to $77 \%$ in $843 \mathrm{~B}$. In an artificial inoculation test at IAC and under natural conditions at two locations with high disease incidence in northern India (Hisar and Gwalior), ICMB 92666 was free of smut, whereas $841 \mathrm{~A}$, a commercial malesterile line of similar height and maturity, had 22 to $41 \%$ smut.

In yield trials conducted in four environments, ICMB 92666 had a mean height of $1.4 \mathrm{~m}$, required $51 \mathrm{~d}$ from seeding to $50 \%$ flowering, and had a mean grain yield of $1.66 \mathrm{tha}^{-1}$, which was $15 \%$ less than ICMB 88004, a commercial male-sterile line of similar maturity and $14 \mathrm{~cm}$ shorter height. ICMB 92666 has good tillering, small panicles $(17.5 \mathrm{~cm})$ that taper towards the tip, and large seed size (10.5 g 1000 seed $\left.^{-1}\right)$. ICMA 92666 and ICMB 92666 set 70 to $90 \%$ seed under open pollination in the main panicle. These lines have creamy anthers and gray - brown seed of globular shape. Male sterility of ICMA 92666 has been stable across seasons and sites.

Seed of ICMA 92666 and ICMB 92666 will be maintained by the Genetic Enhancement Division, ICRISAT Asia Center, and have been distributed to several hybrid breeding programs in India. Small quantities of seed of these two lines will be provided upon request.

\section{K. N. RAI, * R. P. THAKUR, AND A. S. RAO (3)}

\section{References and Notes}

1. Anand Kumar, D.J. Andrews, R.P. Jain, and S.D. Singh. 1984. ICMA-1 and ICMB-1 pearl millet parental lines with $A_{1}$ cytoplasmic-genic male sterility system. Crop Sci. 24:832.

2. Thakur, R.P., K.N. Rai, S.B. King, and V.P. Rao. 1993. Identification and utilization of ergot resistance in pear millet. Res. Bull. 17. ICRISAT, Patanchen, India.

3. K.N. Rai and A.S. Rao, Genetic Enhancement Division; R.P. Thakur, Crop Protection Division, Patancheru 502 324, Andhra Pradesh, India. Approved as Journal Article no. 1992 by ICRISAT. Accepted 30 June 1997. *Corresponding author (k.rai@cgnet.com) (for 1998, krai@unlvm. unl.edu).

Published in Crop Sci. 38:575 (1998).

\section{Registration of Smut-Resistant Pearl Millet Parental Lines ICMA 88006 and ICMB 88006}

ICMB 88006 (Reg. no. PL-29, PI 596507) pearl millet [Pennisetum glaucum (L.) R. Br.] is the maintainer line of ICMA 88006 (Reg. no. PL-30, PI 596508). ICMA 88006 and ICMB 88006 were developed and released in 1996 by ICRISAT Asia Center, Patancheru, AP, India, for use in hybrid breeding programs. ICMA 88006 is resistant to smut [caused by Moesziomyces penicillariae (Bref.) K. Vánky; syn. Tolyposporium penicillariae Bref.] and downy mildew [caused by Sclerospora graminicola (Sacc.) J. Schröt.].

The male-sterile line, ICMA 88006, derives its $A_{1}$ cytoplasm from ICMA-1 (81A) (1). ICMB 88006 was developed by crossing 843B (=BKM 2068) with a smut- and downy mildew-resistant line derived from a cross between $81 \mathrm{~B}$ and a smut resistant source line (SRL 53-1). 843A (= AKM 2068) and 843B were introduced into India in 1982 by ICRISAT from Fort Hays Experimental Station, Kansas State University. SRL 53-1 was developed at ICRISAT Asia Center (IAC) as a source of smut resistance. This line is also resistant to downy mildew. The cross involving $843 \mathrm{~B}$ was made in the 1982 dry season and the $F_{1}$ was planted in the 1982 rainy season. Pedigree selection up to $F_{4}$ generation, followed by three generations of bulk pedigree selection for high grain yield, large seed size, earliness, and high levels of resistance to smut and downy mildew produced a maintainer $F_{7}$ progeny in 1986. Its male-sterile hybrid on $81 \mathrm{~A}$ and the $\mathrm{F}_{8}$ progeny were established as an A-B pair during the 1986 rainy season. Individual plants from the $F_{8}$ progeny were further selfed and backcrossed onto individual plants of the sterile hybrid. This process of selfing in the maintainer progeny with concurrent backcrossing of individual plants onto individual plants of the sterile backcross progeny led to a malesterile $\mathrm{BC}_{4}$ progeny and the counterpart $\mathrm{B}$-line ( $\mathrm{F}_{11}$ progeny). Two additional backcrosses were made using bulk pollen from the $\mathrm{B}$ line to develop ICMA 88006 and the selfed bulk of the B-line as ICMB 88006 in 1988.

In yield trials conducted in 11 year-location environments in India, ICMA 88006 had $1.62 \mathrm{t} \mathrm{ha}^{-1}$ mean grain yield, $1.1 \mathrm{~m}$ plant height, and 2.2 panicles plant $^{-1}$, which was similar to a malesterile line $81 \mathrm{~A}(2)$. ICMA 88006 required $50 \mathrm{~d}$ to flowering $(4 \mathrm{~d}$ earlier than $81 \mathrm{~A}$ ) and had a 1000 -seed mass of $12.7 \mathrm{~g}, 84 \%$ higher than that of $81 \mathrm{~A}$. Smut severity in smut nurseries at IAC ranged from 0 to $1 \%$ in ICMA 88006 and from 17 to $68 \%$ in $81 \mathrm{~A}$. Downy mildew incidence in downy mildew nurseries and 
greenhouse inoculation tests at IAC ranged from 11 to $20 \%$ in ICMA 88006 and from 40 to $42 \%$ in $81 \mathrm{~A}$. The general combining ability of ICMA 88006 for grain yield was similar to that of $81 \mathrm{~A}$ (2).

Male sterility of ICMA 88006 has been observed to be stable across rainy and postrainy seasons in India. ICMB 88006 is a moderate pollen producer. The stigmas of both lines remain receptive for 2 to $3 \mathrm{~d}$, which is 1 to $2 \mathrm{~d}$ less than that of 81A. ICMA 88006 and ICMB 88006 set 80 to $90 \%$ seed on the main panicle. These lines have a purple leaf sheath base, while the stem base and internodes are green. Anther color is light brick-red. Panicles are semicompact, candle-shaped and short $(16 \mathrm{~cm})$. Seeds have globular shape and gray color.

Seed of ICMA 88006 and ICMB 88006 will be maintained by the Genetic Enhancement Division, ICRISAT Asia Center. Seed of these lines has been made available to several seed-producing agencies in India and to research programs worldwide. Small quantities of seed will be provided upon request.

\section{K. N. RAI,* R. P. THAKUR, AND A. S. RAO (3)}

\section{References and Notes}

1. Anand Kumar, D.J. Andrews, R.P. Jain, and S.D. Singh. 1984. ICMA-1 and ICMB-1 pearl millet parental lines with $\mathrm{A}_{1}$ cytoplasmic-genic male sterility system. Crop Sci. 24:832.

2. Rai, K.N., and A.S. Rao. 1994. Performance of three diverse male-sterile lines in pearl millet. Crop Improv. 21:1-8.

3. K.N. Rai and A.S. Rao, Genetic Enhancement Div., and R.P. Thakur, Crop Protection Div., ICRISAT Asia Center, Patancheru 502 324, Andhra Pradesh, India. ICRISAT Journal Article no. JA 1994. Registration by CSSA. Accepted 30 June 1997. *Comesponding author (k.rai@cgnet.com) (for 1998, krai@unlvm.unl.edu).

Published in Crop Sci. 38:575-576 (1998).

\section{Registration of ICMR 501 Pearl Millet Topcross Pollinator Parental Line}

ICMR 501 pearl millet [Pennisetum glaucum (L.) R. Br.] parental line (Reg. no. PL-33, PI 597491) was developed by ICRISAT (Int. Crops Res. Inst. for the Semi-Arid Tropics, Patancheru, India, and released on 15 July 1996 . ICMR 501 was bred by random-mating 11 phenotypically similar inbred lines derived from Bold Seeded Early Composite (BSEC) (6) and the ICRISAT 1989 Potential RLine Trial. ICMR 501 is the pollinator population of pearl millet grain hybrid GICH 501 (Jawahar Bajra Hybrid-1).

Nearly 280 inbred lines, derived by selfing five generations from the BSEC third-cycle bulk (BSEC C3), were included in an unreplicated nursery in the 1989 dry season (summer) and were evaluated for seed size and uniformity at maturity. They were also screened at the seedling stage in a greenhouse (3) for resistance to downy mildew [caused by Sclerospora graminicola (Sacc.) J. Schrơt.] and grown under artificially extended daylength $(14.7 \mathrm{~h})$ in the summer of 1989 , to eliminate late flowering lines. The 40 selected inbred lines (downy mildew incidence $<10 \%$ and early flowering) were evaluated at multiple locations for phenotypic uniformity and early maturity in the 1989 rainy season. In the same season, they were also screened in the field for resistance to downy mildew (5). Eleven inbred lines that were most resistant to downy mildew ( $<10 \%$ incidence) in the greenhouse seedling test were randomly crossed in the 1990 dry season to produce $20 \mathrm{~F}_{1}$ crosses.

In a second cycle of random mating during the 1990 rainy season, an equal quantity of bulk pollen was collected from 10 plants of each $F_{1}$ progeny. Twenty heads of each $F_{1}$ were used as female parents. Bulk seed obtained by mixing an equal quantity of seed from each $F_{1}$ female was designated Potential Restorer Line
Bold Seeded Early Composite Topcross Pollinator 1 (PRLBSEC TCP1). This line was later renamed ICMR 501 in the All India Coordinated Pearl Millet Improvement Project (AICPMIP) Trials.

ICMR 501 showed high and stable resistance to downy mildew in India. ICMR 501 was tested in the International Pearl Millet Downy Mildew Nursery in India (2). Across four locations over 3 yr (1993-1995), ICMR 501 had a mean downy mildew incidence of $<1.0 \%$, compared with $6.7 \%$ on stable resistant inbred $P \quad 7-4$ (ICML 12) (4) and $80 \%$ on susceptible inbred 7042(S).

Approximately $80 \mathrm{~S}_{1}$ lines were selected from ICMR 501 in the 1994 rainy season and selfed to produce $612 S_{2}$ lines in 1995 dry season. These were evaluated for resistance to downy mildew in a greenhouse. Twenty-five families containing $180 \mathrm{~S}_{2}$ lines with downy mildew incidence $<10 \%$ were random mated to produce ICMR 501 (PRLBSEC TCP1) Nucleus Seed I.

Grain yield of ICMR 501 was $3825 \mathrm{~kg} \mathrm{ha}^{-1}$ at Patancheru, India (19 $9^{\circ} \mathrm{N}$ lat), which was comparable to WC-C75 $(3835 \mathrm{~kg}$ $\mathrm{ha}^{-1}$ ). ICMR 501 flowers early (43 to $44 \mathrm{~d}$ to $50 \%$ flowering) and produces fertile hybrids on ICMA 1 (1) and other male-sterile lines having $A_{1}$ cytoplasm. It is phenotypically uniform and is a source of stable downy mildew resistance.

Panicles of ICMR 501 are of medium length $(18$ to $21 \mathrm{~cm}$ ), compact to semicompact, and conical in shape. It has large seed

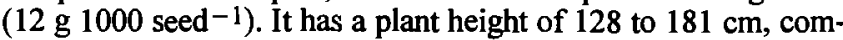
pared with 150 to $212 \mathrm{~cm}$ for WC-C75. ICMR 501 has a low frequency (approximately 20\%) of plants with pubescent leaves.

Seed of ICMR 501 Nucleus Seed I has been made available to many public and private institutions in India and will be maintained by the Genetic Enhancement Division, ICRISAT Asia Center, Patancheru, India. A sample of the original seed stock is preserved in the ICRISAT genebank.

\section{B. S. Talukdar, * A. M. RaO, P. P. Prakash Babu,} AND J. R. WITCOMBE (7)

\section{References and Notes}

1. Anand Kumar, D.J. Andrews, R.P. Jain, and S.D. Singh. 1984. ICMA-1 and ICMB-1 pearl millet parental lines with A1 cytoplasmic-genic male sterility system. Crop Sci. 24:832.

2. ICRISAT. 1978. Report of the Intemational Pearl Millet Downy Mildew Nursery (IPMDMN). ICRISAT, Patancheru, India.

3. Singh, S.D., and R. Gopinath. 1985. A seedling inoculation technique for detecting downy mildew resistance in pearl millet. Plant Dis. 69:582-584.

4. Singh, S.D., S.B. King, and P. Malla Reddy. 1990. Registration of five pearl millet germplasm sources with stable resistance to downy mildew. Crop Sci. 30:1164.

5. William, R.J., S.D. Singh, and M.N. Pawar. 1981. An improved field screening technique for downy mildew resistance in pearl millet. Plant Dis. 65:239-241.

6. Witcombe, J.R., M.N.V.R. Rao, B.S. Talukdar, S.D. Singh, and A.M. Rao. 1996. Registration of ICMR 312 pearl millet topcross pollinator germplasm. Crop Sci. 36:471.

7. B.S. Talukdar and P.P. Prakash Babu, Genetic Enhancement Division, ICRISAT Asia Center, Patancheru, A.P. 502 324, India; A.M. Rao, Sandoz (India) Ltd., Coimbatore, Tamil Nadu, India; and J.R. Witcombe, Dep. for International Development (DFID) Plant Sciences Res. Program, Ctr. for Arid Zone Studies, Univ. of Wales, Bangor, Gwynedd LL57 2UW, UK. ICRISAT Joumal Article no. 2026. Registration by CSSA Accepted 30 Sept. 1997. *Corresponding author (b.talukdar@cgnet.com).

The authors are thankful to Drs. G.S. Chauhan and U. Singh Santoshi for testing the topcross hybrid GICH 501 in research station and AICPMIP trials, and for taking action necessary to permit its release in the state of Madhya Pradesh, India. The authors are also thankful to Dr. S.D. Singh for providing the data for evaluation of ICMR 501 (PRLBSEC TCP 1) for resistance to downy mildew and to Dr. C.T. Hash for help in making the release proposal of GICH 501 and also for reviewing the manuscript. The contribution of All India Coordinated Pearl Millet Improvement Project (AICPMIP) scientists in the multilocational evaluation of GICH 501 is gratefully acknowledged.

Published in Crop Sci. 38:576 (1998). 